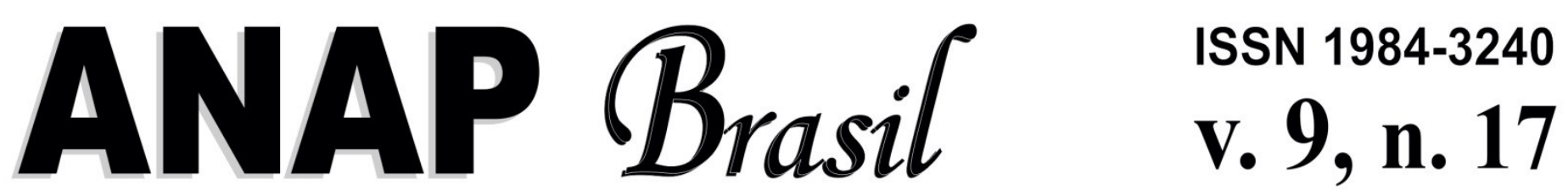

\title{
Estudo da Cobertura Vegetal e Modelo Chuva x Vazão na Sub-Bacia do Córrego do Luciano Município de Jardinópolis-SP
}

Study of Cover Vegetation and Hydrologic Model of Sub-Basin Luciano Stream Located in the municipality of Jardinópolis-SP

Estudio de la Cobertura Vegetal y el Modelo Hidráulico de la Subcuenca del Arroyo Luciano del Municipio de Jardinópolis-SP

Sâmia Momesso Marques Mestranda em Engenharia Civil (Recursos Hídricos e Tecnologia Ambiental), UNESP, Brasil samia.momesso@gmail.com

Gustavo Zitei Vicente Mestrando em Engenharia Civil (Recursos Hídricos e Tecnologia Ambiental), UNESP, Brasil gustavo.zitei@gmai.com

César Gustavo da Rocha Lima Professor Doutor, UNESP, Brasil. etaugustus@hotmai.com 


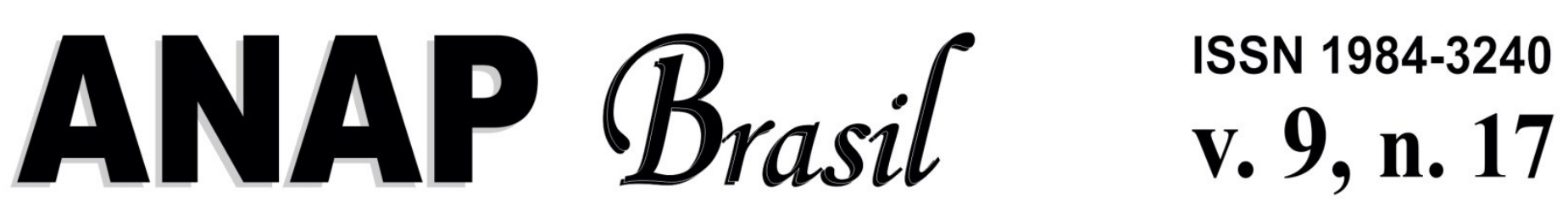

\section{INTRODUÇ̃̃o}

Embora tenha seu valor negligenciado pelas autoridades públicas e sociedade em geral, as áreas verdes desempenham papel tão importante para os ambientes urbanos quanto a infraestrutura construída, chamada de infraestrutura cinza (VASCONCELLOS, 2011; SCHÄFFLER e SWILLING, 2013).

Essas áreas, de acordo com CCAP (2011), podem trazer diversos benefícios dentre os quais podemos citar o equilíbrio térmico em ambientes urbanos, a melhoria da qualidade do ar, o combate a enchentes e a redução do potencial de erodibilidade das chuvas, pela redução da velocidade dos escoamentos superficiais.

As chamadas Infraestruturas Verdes têm papel fundamental na restauração do equilíbrio ambiental frente à crescente urbanização. Elas podem ser definidas, conforme Vasconcellos (2011), como redes interconectadas e estrategicamente planejadas compostas por áreas naturais, ambientes rurais e outras áreas livres que têm como papel a conservação dos valores e funções dos ecossistemas naturais, proporcionando benefícios à vida humana e silvestre.

Assim sendo, a infraestrutura verde demanda de uma abordagem holística do uso e ocupação do solo de bacias hidrográficas urbanizadas, enfatizando a integração dos objetivos ambientais e econômicos no planejamento da paisagem. (VASCONCELLOS, 2011).

Nesse contexto, o mapeamento de uso e ocupação do solo e o monitoramento de sua dinâmica são etapas importantes para fins de planejamento e manejo sustentável dos recursos naturais (BRASIL, 2003).

A associação de tecnologias de sensoriamento remoto com Sistemas de Informações Geográficas (SIG) serve como ferramenta no processo de análise da dinâmica de uso e ocupação do solo já que, segundo Nardini (2009), oferecem uma representação fiel das características da paisagem em um dado momento.

Além disso, o comportamento hidrológico de uma bacia hidrográfica pode ser afetado por ações antrópicas, uma vez que as alterações provocadas pelas atividades econômicas e sociais na paisagem interferem nos processos do ciclo hidrológico (TONELLO, 2005).

Portanto, a integração do SIG com modelos hidrológicos permite a realização de simulações da contribuição da infraestrutura verde perante às alterações antrópicas do regime hidrológico.

\section{OBJETIVO}

O presente trabalho teve como objetivo fazer um estudo das alterações de uso e ocupação do solo na Sub-bacia do Córrego do Luciano, avaliada nos anos de 1995, 2005 e 2015, para entender como a existência da infraestrutura verde pode impactar no ambiente urbanizado.

No que tange aos efeitos das alterações da paisagem sobre o regime hidrológico da região, foi empregado o modelo Chuva $x$ Vazão auxiliado por análises de uso e ocupação do solo. 


\section{ANAP Brasil

\section{MÉTODO DE ANÁLISE}

\section{Caracterização da Área}

O presente estudo foi realizado na Sub-bacia Hidrográfica do Córrego do Luciano, que está localizada no município de Jardinópolis-SP. O Córrego do Luciano se encontra entre as

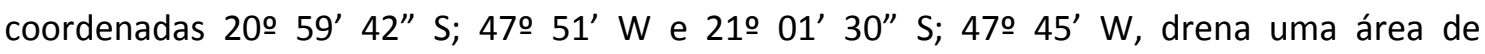
aproximadamente $18,4 \mathrm{~km}^{2}$, tem seu exutório no Ribeirão São Pedro, que por fim deságua no Rio Pardo.

O município de Jardinópolis registrou no período de 1995 a 2015 um acréscimo populacional na ordem de 13.500 habitantes, o que motivou uma expansão urbana do município e, por sua vez, afetou a sub-bacia do córrego do Luciano provocando o surgimento de novos empreendimentos imobiliários e loteamentos.

\section{Procedimentos Metodológicos}

\section{Uso e Ocupação}

Como materiais foram utilizadas as cartas topográficas da região, obtidas a partir do banco de dados do IBGE, imagens de satélite para os anos de 1995, 2005 e 2015, nas quais tomou-se o cuidado de escolher imagens do mesmo período do ano, todas do mês de julho e obtidas a partir do banco de imagens do INPE. Para os anos de 1995 e 2005 foram usadas imagens do sensor TM do Landsat-5, nas bandas $1(\mathrm{~b}), 2(\mathrm{~g})$ e $3(\mathrm{r})$ para os espectros de azul, verde e vermelho respectivamente. Já para o ano de 2015 o sensor OLI do Landsat-8 com imagens das bandas 2(b), 3(g) e 4(r) nas faixas de azul, verde e vermelho, respectivamente.

As imagens foram georreferenciadas no Software Spring 5.2.7 e os limites da bacia hidrográfica foram traçados com auxílio da carta topográfica da região. Posteriormente, as imagens de satélite foram recortadas de forma a conter apenas a sub-bacia hidrográfica em estudo, a fim de evitar interferências das áreas circundantes no processo de classificação das imagens (Figura 1). 


\section{ANAP Brasil

Figura 1 - Sub-bacia do Córrego do Luciano em imagens de satélite nos anos de 1995 (a), 2005 (b) e 2015 (c)

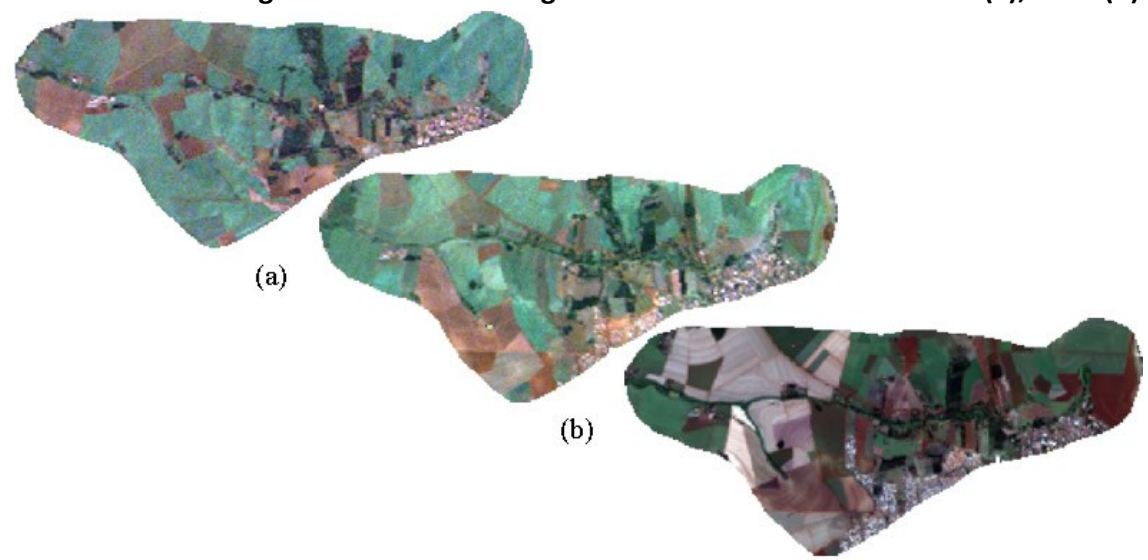

(c)

Fonte: Elaborado pelos autores.

Assim, as imagens foram classificadas de acordo com 5 classes distintas de uso e ocupação do solo, sendo elas: pós-colheita, solo exposto, agricultura, vegetação arbórea e urbano. A classificação foi feita de forma supervisionada com auxílio do método de segmentação das imagens, adotando em todos os casos o valor 2 para o grau de similaridade. Após as atividades de treinamento realizadas, com o máximo de precisão na coleta de regiões, procedeu-se a classificação final com o emprego do algoritmo Bhattacharya.

Ao final do processo de classificação das imagens, foram medidas as áreas ocupadas por cada classe de uso e ocupação do solo, para que se pudesse aplicar o modelo hidrológico da curva número.

\section{Modelo Hidrológico Chuva x Vazão}

O Serviço de Consevação dos Solos dos Estados Unidos sugeriu em 1986, por meio da publicação técnica "Urban Hydrology for Small Watersheds (TR-55)" (USDA, 1986), um método para estimativa do escoamento superficial direto em pequenas bacias hidrográficas, que ficou conhecido como SCS ou Curva Número. O método se relaciona diretamente com o tipo de solo da bacia hidrográfica, suas coberturas e condições de umidade por meio da classe hidrológica do solo e da curva número, respectivamente.

Segundo Tucci (1993), as classes hidrológicas dos solos podem ser resumidas pelo quadro que segue. 


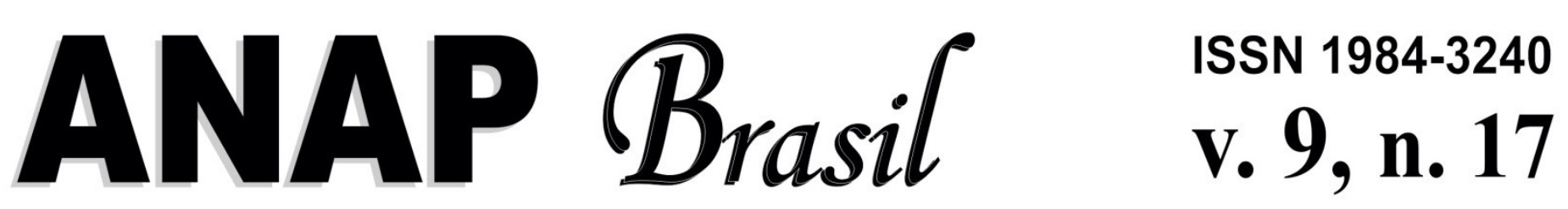

Quadro 1 - Classificação hidrológica dos solos brasileiros

\begin{tabular}{|c|c|}
\hline Classe & Classificação hidrológica do solo \\
\hline A & $\begin{array}{l}\text { Solos que produzem baixo escoamento superficial e alta infiltração. Solos arenosos } \\
\text { profundos com pouco silte e argila. }\end{array}$ \\
\hline $\mathrm{B}$ & $\begin{array}{l}\text { Solos menos permeáveis do que o anterior, solos arenosos menos profundos do que o } \\
\text { tipo A e com permeabilidade superior à média. }\end{array}$ \\
\hline C & $\begin{array}{l}\text { Solos que geram escoamento superficial acima da média e com capacidade de infiltração } \\
\text { abaixo da média, contendo percentagem considerável de argila e pouco profundos. }\end{array}$ \\
\hline $\mathrm{D}$ & $\begin{array}{l}\text { Solos contendo argilas expansivas, pouco profundos e com muito baixa capacidade de } \\
\text { infiltração, gerando a maior proporção de escoamento superficial. }\end{array}$ \\
\hline
\end{tabular}

Fonte: Adaptado de Tucci (1993).

Para cada conjunto de classe hidrológica e cobertura do solo, são atribuídos diferentes valores de $\mathrm{CN}$. Além disso, as condições de umidade influenciam diretamente nesses valores. O solo pode estar em três condições de umidade: seco, normal (capacidade de campo) ou saturado. Sendo assim, é necessário primeiramente definir o valor de $\mathrm{CN}$ na condição normal do solo para posteriormente corrigir o valor encontrado por meio de tabelas que relacionam o valor de $\mathrm{CN}$ com as condições normais e seus respectivos valores nas condições seca e saturada. Em uma bacia hidrográfica, onde existem diversos tipos e usos do solo, o CN é calculado conforme a Equação 1:

$$
C N=\frac{\sum_{i=1}^{n} C N_{i} \cdot A_{i}}{A}
$$

Equação 1

Onde:

$C N$ : Curva número da bacia hidrográfica;

$C N_{i}$ : curva número da região;

$A_{i}$ : área da região; e

$A$ : área total da bacia hidrográfica.

De posse do valor de $\mathrm{CN}$ para a bacia hidrográfica, é possível determinar o parâmetro denominado $S$, que diz respeito às condições de cobertura e do tipo de solo.

$$
S=\frac{24500}{C N}-254
$$

Equação 2

Onde:

S: Condição de cobertura e tipo de solo. 
ANAP Brasil $\quad \begin{aligned} & { }^{155 N} 1984-3240 \\ & \text { v. } 9, \text { n. } 17\end{aligned}$

\section{REVISTA CIENTÍFICA $\quad 2016$}

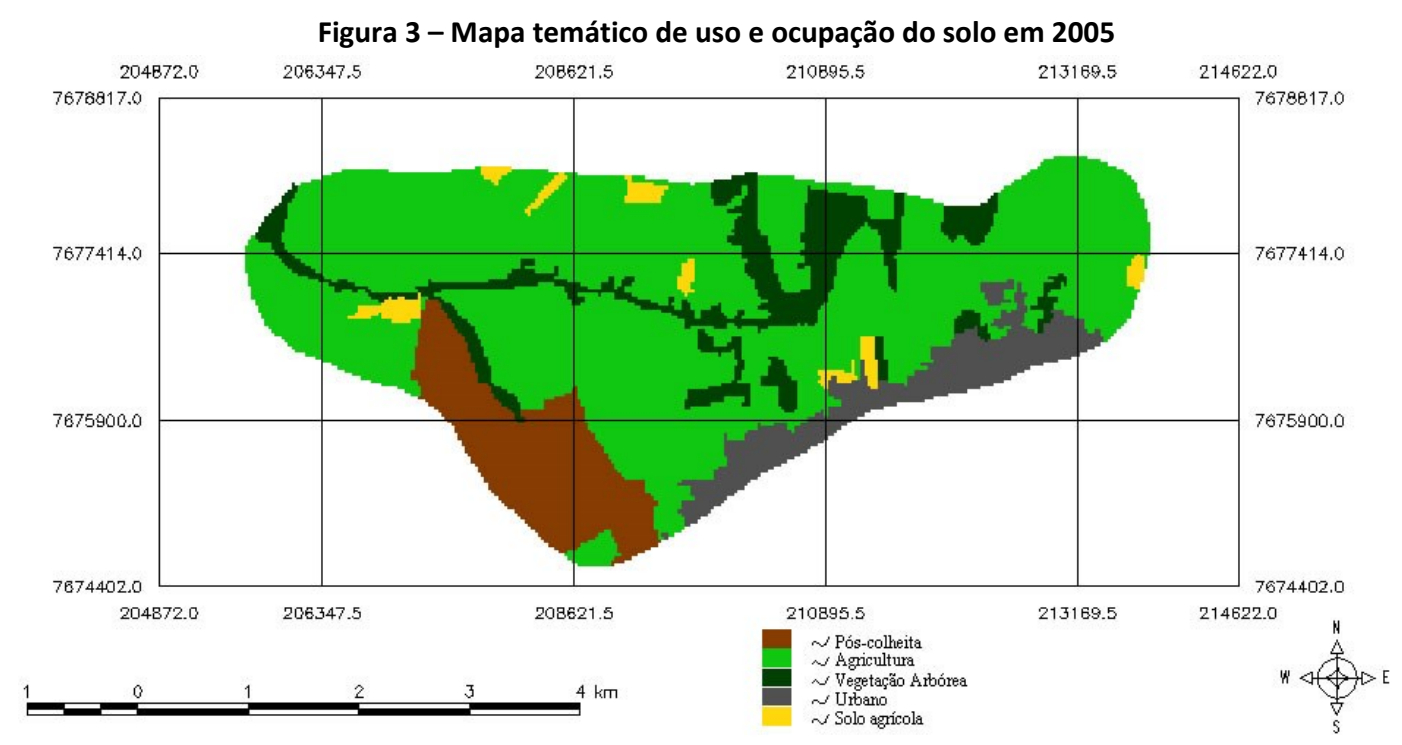

Fonte: Elaborado pelos autores.

Figura 4 - Mapa temático de uso e ocupação do solo em 2015

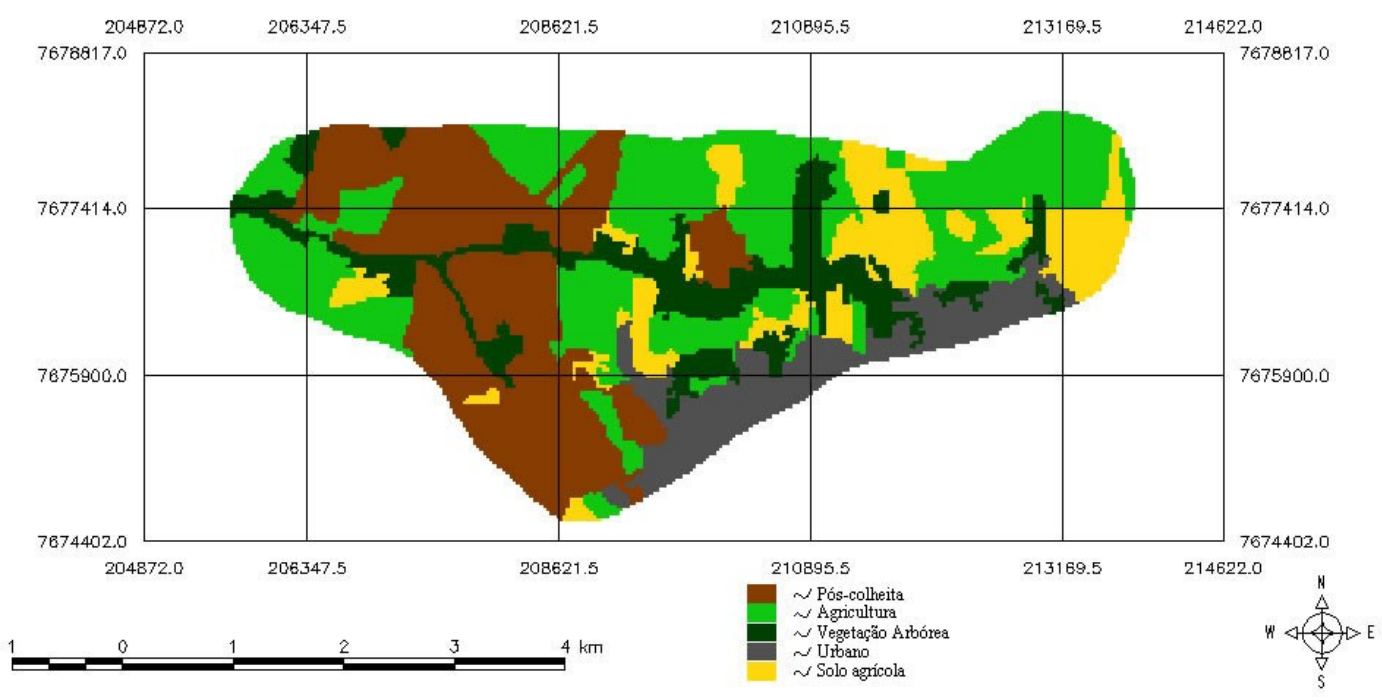

Fonte: Elaborado pelos autores. 


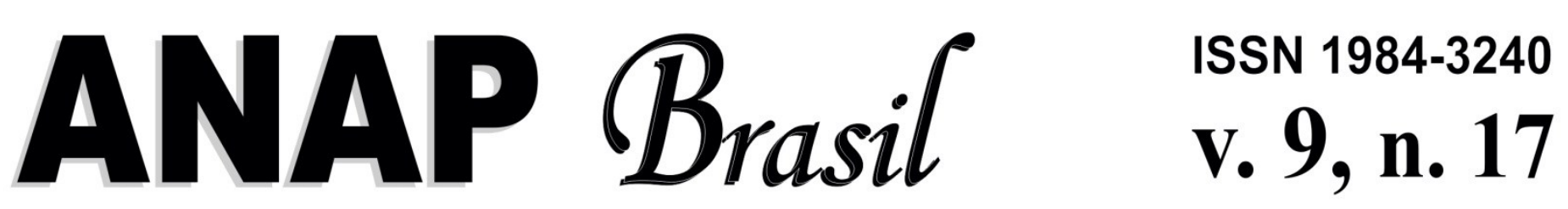

REVISTA CIENTÍFICA 2016

Tabela 1 - Áreas das classes de uso e ocupação do solo

\begin{tabular}{|c|c|c|c|c|c|c|}
\hline \multirow{3}{*}{ Classe Área } & \multirow{2}{*}{\multicolumn{2}{|c|}{1995}} & \multirow{2}{*}{\multicolumn{2}{|c|}{2005}} & & \\
\hline & & & & & \multicolumn{2}{|c|}{2015} \\
\hline & $\left(\mathrm{km}^{2}\right)$ & (\%) & $\left(\mathrm{km}^{2}\right)$ & (\%) & $\left(\mathrm{km}^{2}\right)$ & (\%) \\
\hline Pós-colheita & 2,8 & 15,2 & 2 & 10,9 & 5,3 & 28,8 \\
\hline Agricultura & 10,9 & 59,2 & 12,3 & 66,9 & 6,2 & 33,7 \\
\hline Vegetação arbórea & 2 & 10,9 & 2,2 & 11,9 & 2,6 & 14,1 \\
\hline Urbano & 0,8 & 4,4 & 1,5 & 8,1 & 1,9 & 10,3 \\
\hline Solo Exposto & 1,9 & 10,3 & 0,4 & 2,2 & 2,4 & 13,1 \\
\hline Total & 18,4 & 100 & 18,4 & 100 & 18,4 & 100 \\
\hline
\end{tabular}

Fonte: Elaborado pelos autores.

Segundo dados do site de Informação dos Municípios Paulistas (IMP, 2016), a população do município de Jardinópolis passou de 26.999 em 1995 para 40.493 habitantes em 2015. Com base nesse dado, a Tabela 1 permite observar o crescimento das áreas urbanas em detrimento das áreas de agricultura, resultado do processo de loteamento que a região sofreu no período analisado em detrimento ao crescimento populacional.

De acordo com Conselho Regional de Desenvolvimento Rural Sustentável (CRDR, 2011), o solo da região onde a Sub-bacia do córrego do Luciano está inserida recebe a classificação pedológica Latossolo Roxo. Segundo Sartori et al. (2005) o Latossolo Roxo encontra-se, em termos hidrológicos, na Classe A, descrita no Quadro 1.

Levando-se em consideração que a classe definida como pós-colheita é referente às áreas de solo exposto devido à colheita da cana-de-açúcar, que pode ser considerada uma cultura anual e, sendo assim, estas áreas estarão cobertas por esta cultura durante a maior parte do ano, foram elaborados dois cenários: o cenário 1 (C1), onde as regiões de pós-colheita foram consideradas como regiões de solo exposto e o cenário 2 (C2), no qual as regiões de póscolheita foram consideradas regiões de agricultura, o que deve ser mais notado ao longo do ano.

Desta forma foi possível escolher os valores de CN para cada classe de uso do solo na sub-bacia conforme USDA (1986), esses valores são apresentados na Tabela 2. 


\section{ANAP $B_{\text {rasil }}$

Tabela 2 - Valores de CN adotados para a região (USDA, 1986)

\begin{tabular}{lcc}
\hline & $\mathbf{C 1}$ & $\mathbf{C 2}$ \\
\cline { 2 - 3 } Cobertura do solo & $\mathbf{C N}_{\mathbf{i}}$ & $\mathbf{C N}_{\mathbf{i}}$ \\
\hline Pós-colheita & 77 & 62 \\
Agricultura & 62 & 62 \\
Vegetação arbórea & 45 & 45 \\
Urbano & 77 & 77 \\
Solo Exposto & 77 & 77 \\
\hline
\end{tabular}

Fonte: Elaborado pelos autores.

Para cada cenário e cada ano, foram calculados os valores do $\mathrm{CN}$ da bacia, utilizando-se a Equação 1 e os valores de S, pela Equação 2. Os valores calculados estão apresentados na Tabela 3.

Tabela 3 - Valores calculados de $\mathrm{CN}$ e $\mathrm{S}$

\begin{tabular}{ccccc}
\hline & \multicolumn{2}{c}{ C1 } & \multicolumn{2}{c}{ C2 } \\
\cline { 2 - 5 } Ano & CN & S & CN & S \\
\hline 1995 & 64,60 & 139,2 & 62,28 & 153,8 \\
2005 & 63,19 & 148,0 & 61,53 & 158,8 \\
2015 & 67,42 & 122,7 & 63,08 & 148,6 \\
\hline
\end{tabular}

Fonte: Elaborado pelos autores.

Com os valores de $\mathrm{CN}$ e S calculados e empregando-se a Equação 3, foram elaborados gráficos de Precipitação x Vazão para os cenários 1 e 2, que estão representados pelos Gráficos 1 e 2, respectivamente. 


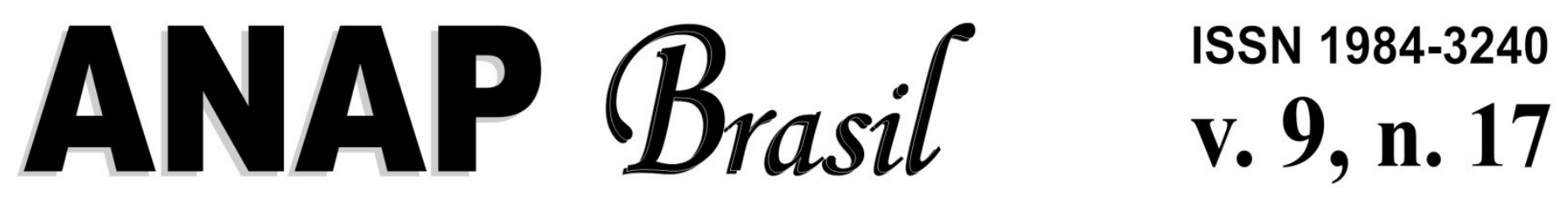

REVISTA C I ENTÍFICA

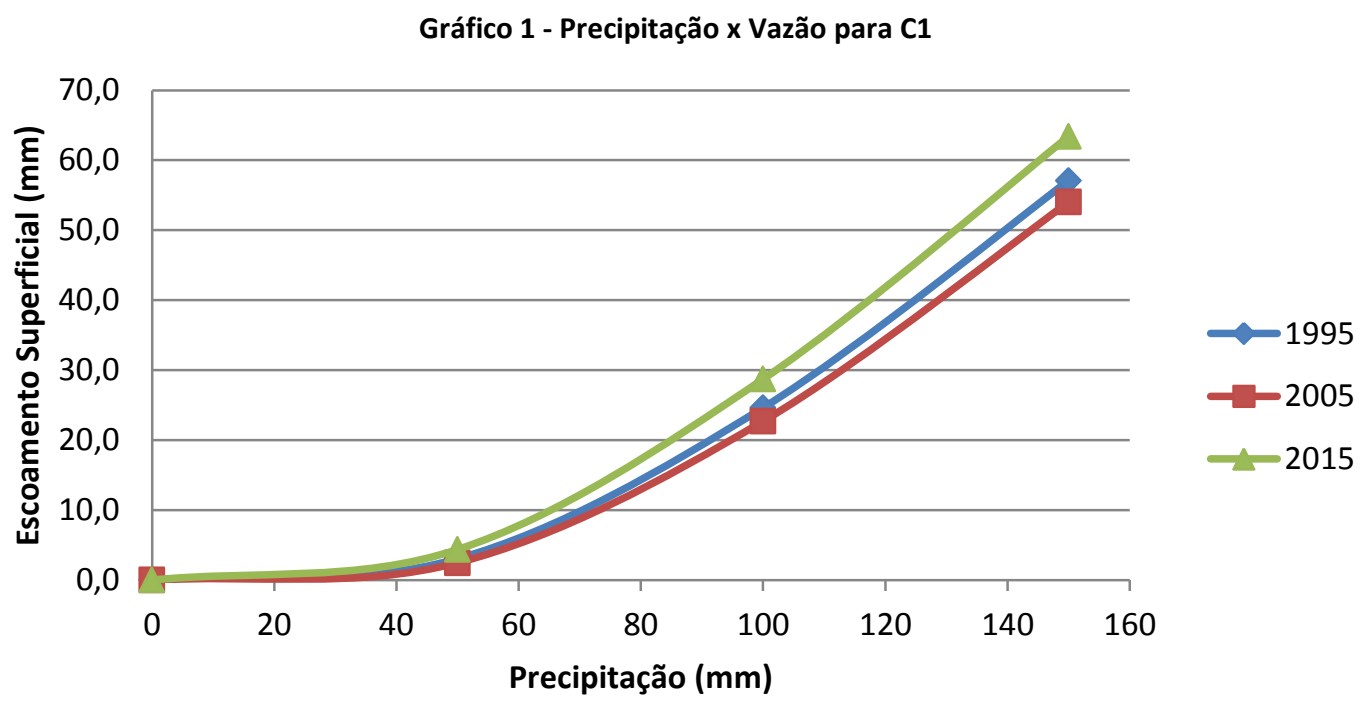

Fonte: Elaborado pelos autores.

Quando analisado o 


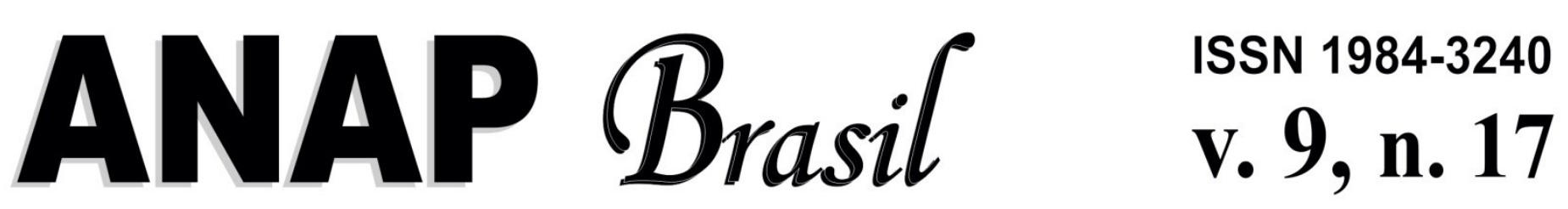

Gráfico 2 : Precipitação x Vazão para C2

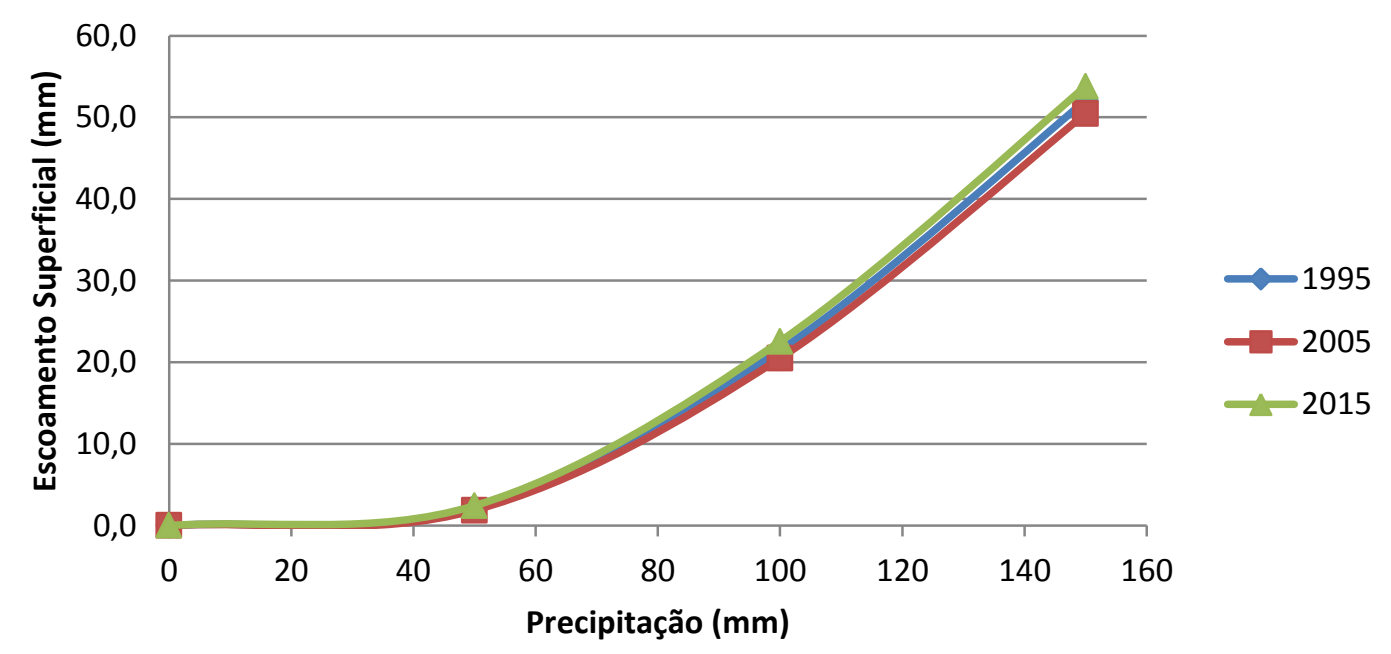

Fonte: Elaborado pelos autores.

Ao analisar o Erro! Fonte de referência não encontrada., é possível notar que há um incremento na lâmina escoada quando comparados os anos de 1995 e 2015, porém o aumento não é tão significativo quando comparado ao apresentado no cenário 1. Apesar da infraestrutura cinza ter aumentado em quase $138 \%$ no período, houve um acréscimo significativo de áreas de vegetação arbórea, na ordem de 30\%, o que possibilitou que os comportamentos hidrológicos não apresentassem grandes alterações no período estudado.

Novamente o ano de 2005 apresentou decréscimo da lâmina escoada em relação a 1995, o que ocorreu devido a dois fatores: a redução de aproximadamente $78,3 \%$ das áreas de solo exposto, e ao aumento das áreas de vegetação arbórea colaborando para a infraestrutura verde.

Quando comparamos os cenários 1 e 2, podemos notar uma diferença alarmante: para uma precipitação de $150 \mathrm{~mm}$ no ano de 2015, as respostas são de 63,4 mm (C1) e 53,8 mm (C2), ou seja, um acréscimo de aproximadamente $18 \%$ na lâmina escoada nos períodos pós-colheita, quando as áreas cultivadas ficam completamente expostas.

Tal acréscimo pode desencadear danos, devido ao aumento do potencial de erosividade das chuvas, podendo levar ao assoreamento do córrego e a perda de potencial agrícola da região. Além disso, caso a seção do exutório não suporte toda a vazão escoada nos períodos de cheia, podem gerar alagamentos de regiões nos arredores trazendo transtornos para os agricultores da região. 
